\title{
Influence of material properties on the ballistic performance of ceramics for personal body armour
}

\author{
Christian Kaufmann ${ }^{\mathrm{a}, *}$, Duane Cronin ${ }^{\mathrm{a}}$, Michael Worswick ${ }^{\mathrm{a}}$, Gilles Pageau ${ }^{\mathrm{b}}$ and Andre Beth ${ }^{\mathrm{c}}$ \\ ${ }^{\mathrm{a}}$ University of Waterloo, Department of Mechanical Engineering, 200 University Avenue West, Waterloo, Ontario, \\ Canada N2L $3 G 1$ \\ ${ }^{\mathrm{b}}$ Defence Research Establishment Valcartier, 2459 Pie IX Blvd. North, Val Belair, Quebec, Canada G3J 1X5 \\ ${ }^{\mathrm{c}}$ Barrday, Incorporated 75 Moorefield Street, P.O. Box 790, Cambridge, Ontario, Canada NIR 5W6
}

Received 3 December 2001

Revised 30 May 2002

\begin{abstract}
In support of improved personal armour development, depth of penetration tests have been conducted on four different ceramic materials including alumina, modified alumina, silicon carbide and boron carbide. These experiments consisted of impacting ceramic tiles bonded to aluminum cylinders with 0.50 caliber armour piercing projectiles. The results are presented in terms of ballistic efficiency, and the validity of using ballistic efficiency as a measure of ceramic performance was examined. In addition, the correlation between ballistic performance and ceramic material properties, such as elastic modulus, hardness, spall strength and Hugoniot Elastic Limit, has been considered.
\end{abstract}

\section{Introduction}

Advances in ceramic/composite armor materials have resulted in improved personal systems that are lightweight and provide a significant amount of protection. However, increasing threats in the form of large caliber and armour-piercing (AP) rounds has led to the need for increased protection. To address this issue, existing body armor could be increased in thickness to the point where an AP round would be defeated. Unfortunately, the necessary increase in the weight of the armor may be unacceptable. The goal of the current work is to evaluate ceramics for use in body armour based on ballistic properties and weight.

Conventional armour for defeating AP rounds consists of a ceramic/composite "sandwich" and is known as hybrid armor as shown in Fig. 1. In 1918, it was dis-

*Corresponding author. Tel.: +1 5198884567 x 2346; E-mail: cfkaufma@engmail.uwaterloo.ca. covered that a hard enamel coating on steel improved bullet resistance [1]. Losses of helicopters during the Vietnam War due to lack of a suitable lightweight armor further intensified research and development. Armours that afforded the same degree of protection as steel were required, but at half the weight. Ceramics were then considered as a material for improved armor.

Unfortunately, ceramic tiles alone can only provide a limited amount of protection from projectiles. By supporting the ceramic with a layer that is energy absorbing, the performance of the armor is dramatically increased and the combination of ceramic and composite is lighter than equivalent steel armour. This realization lead to the development of hybrid armor systems which consist of a layer of ceramic and composite bonded together.

The layers that form hybrid armor serve specific purposes in defeating projectiles. The function of the ceramic facing is to destroy the tip of the incoming projectile, distribute the load over a large area of the composite and to decelerate the projectile. The compos- 


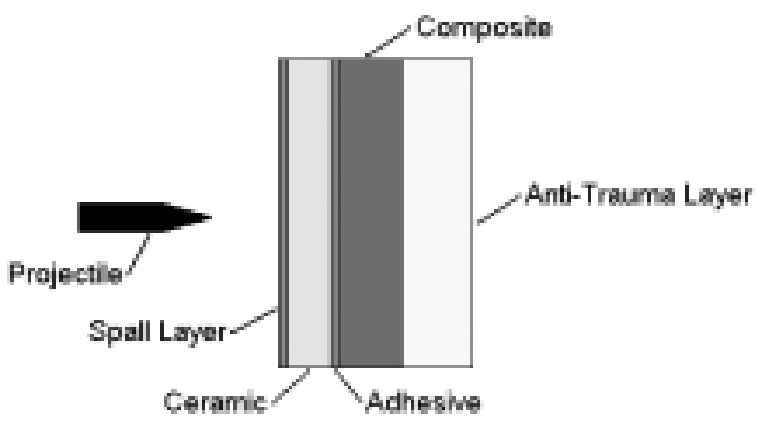

Fig. 1. Hybrid armor example.

Table 1

Thickness and area density of ceramics evaluated

\begin{tabular}{lccccc}
\hline \multirow{2}{*}{$\begin{array}{l}\text { Ceramic type } \\
(-)\end{array}$} & \multicolumn{2}{c}{ Thin example } & & \multicolumn{2}{c}{ Thick example } \\
\cline { 2 - 3 } \cline { 5 - 6 } & $(\mathrm{mm})$ & $\left(\mathrm{kg} / \mathrm{m}^{2}\right)$ & & $(\mathrm{mm})$ & $\left(\mathrm{kg} / \mathrm{m}^{2}\right)$ \\
\hline CERAMOR & 8.73 & 31.97 & & 14.77 & 54.26 \\
CERAMOR Z & 8.63 & 32.33 & & 14.83 & 55.6 \\
HEXOLOY & 11.42 & 36.03 & & 17.75 & 56.13 \\
Ceralloy 546 & 15.25 & 38.32 & & 22.87 & 57.41 \\
\hline
\end{tabular}

ite supports the ceramic and brings the projectile and comminuted ceramic to rest. The performance of each of the individual constituents of a hybrid armor system influences the overall performance of the armor.

Depth of penetration testing provides a means of evaluating ceramics used in ballistic applications for specific projectiles. A 0.50 caliber armour piercing projectile was used in these tests. Past research has also been examined to determine if conclusions drawn about the influence of material properties regarding ceramic performance are still applicable to this study. The ceramics tested in this study were boron carbide (Ceralloy 546), silicon carbide (Hexoloy), alumina (CERAMOR) and modified alumina (CERAMOR-Z). Data regarding the thickness and areal density of the ceramic tiles used in this study may be viewed below in Table 1.

Traditionally, armour has been evaluated by the V50 (i.e. the velocity at which a projectile has a $50 \%$ probability of penetrating the armor) and maximum deformation [2]. Behind Armour Blunt Trauma (BABT) has also been identified as an important injury mechanism to understand when creating ballistic armor, especially for large caliber, high-energy projectiles [3]. BABT is the result of deformation and impact of the rear surface of an armour vest to the torso of the user. BABT can result in fatal events such as rib fractures, pulmonary contusion, cardiac injury and Commotio Cordis even if the projectile has been defeated [3-5]. The better an armour is at dissipating impact energy, the more BABT can be mitigated.

\section{Ceramic failure mechanisms}

Ceramic performs two functions in hybrid armor: the high hardness of the ceramic aids in fracturing the projectile core into fragments, reducing the effectiveness of the AP round, and the ceramic serves to distribute the impact load over a larger area of the backing material reducing the loads and improving ballistic performance.

Projectile impact on ceramic may be simplified if considered in two phases. The first phase deals with the propagation and reflection of compressive and tensile waves within the ceramic. The duration of this phase is on the order of several microseconds.

The initial impact results in a series of radial cracks originating from the bottom of the tile [7]. Next, a fracture front starts to propagate into the ceramic ahead of the projectile. The initial damage originates in the ceramic at a number of points located around the impact site. Shallow co-axial cracks propagate from these points forming a shallow cylinder. The cylindrical cracks then form a fracture conoid that terminates at the back plane of the armor [8]. A fracture cone is fully formed at time $=6(\mathrm{~h} / \mathrm{c})$ where $\mathrm{h}$ is the thickness of the tile and $c$ is the longitudinal speed of sound [6]. For a typical ceramic plate, the formation of the fracture conoid is on the order of a few microseconds [9]. The angle of the fracture conoid depends on a number of factors, such as dynamic loading, but is usually around 65 degrees. After the formation of the fracture conoid, shock degradation of the armor may result [8] due to stress waves generated from the initial impact. These stress waves are initially compressive and travel at the speed of sound in ceramic. Once this wave reaches the free surface of the ceramic, it is reflected and as a tensile wave. The tensile wave fractures the ceramic at any point where the dynamic tensile yield strength is exceeded. These reflected tensile pressure waves are responsible for spall cracks which travel from the back of the ceramic towards the projectile [10]. After formation of the conoid, projectile erosion and flattening continues with slight ceramic penetration [6,8]. In addition, a small amount of comminuted ceramic forms near the projectile impact zone where high pressures are experienced.

The gross structural response of the material is considered as the second phase and concludes when either the projectile or the armor is defeated [8]. The second phase is on the order of several milliseconds in duration [9]. During the second phase, the projectile may be eroded further, depending on the properties of the 


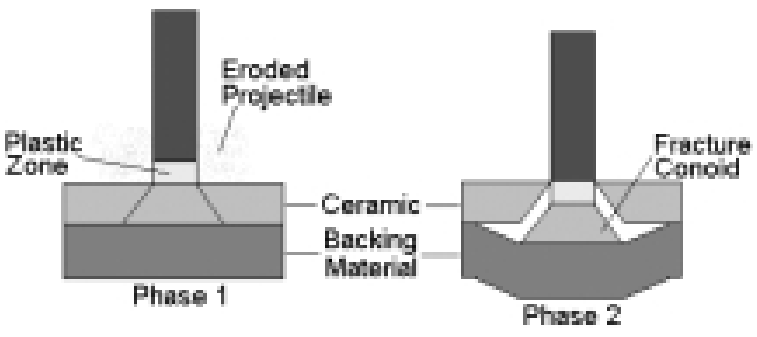

Fig. 2. Failure mechanisms in ceramic tile (modified from [6]).

ceramic. During this phase the conoid of fractured ceramic distributes the impact load of the projectile over a larger area of the backing material compared to the projectile's original diameter. As the backing material deflects, projectile erosion products and comminuted ceramic are forced out of the impact area. The deflection of the backing material also creates volumes for the comminuted ceramic to migrate into. As material migrates away from the impact site, the fracture conoid becomes progressively smaller, distributing the impact load over a smaller portion of backing material than when the fracture conoid was first formed. If the load becomes focused over too small an area, the backing material can fail either by plug shearing or bending [8] for a thin plate or by cratering if the backing is semiinfinite.

\section{Material properties of tested ceramics}

Typical material properties of the tested ceramics are shown in Fig. 3. The values displayed have been normalized by those of high density (99.9\%) alumina.

The influence of material properties on the ballistic performance of ceramic has been examined by several authors and are listed below. These material properties are:

\section{Compressive strength / tile thickness}

Shockey et al. [11] has stated that initial resistance of a ceramic to penetration is provided by the compressive strength of the ceramic. The projectile may be fractured, deformed or deflected depending upon the compressive strength of the ceramic. If the strength of relatively short ratio projectile is exceeded by the ceramic, then the projectile can be defeated. However, longer projectiles may be damaged at impact, but the intact rear portion of the projectile may continue to advance and penetrate the ceramic. Therefore, the compressive strength of the ceramic can aid in defeating a projectile only to a certain extent.

\section{Hardness}

Woodward et al. [12] noted, based on work performed by Rosenberg and Yesherun, that the act of blunting a projectile can severely decrease its ability to penetrate a backing material. If the ceramic is of a sufficient hardness to blunt or otherwise destroy the projectile tip, the ballistic performance of the armour is improved. This observation is reinforced by Den Reijer [8] who stated that the hardness of the ceramic should be greater than that of the penetrator, however, any further increase above this value is not necessary or beneficial.

\section{Density}

It has been stated by various authors $[8,13]$ that low density is beneficial for a target material. Not only does the lower density of the target contribute to lighter weight armour, but it also allows a thicker ceramic to be used without a substantial weight penalty.

\section{Bulk, shear and young's moduli}

The resistance of the ceramic to deformation is also important in defeating a projectile. The material properties that are responsible for resisting deformation to failure are the bulk, shear and Young's moduli [13].

\section{Shear strength}

High shear strength is also advantageous in defeating a projectile. However, the ceramic must be of sufficient thickness compared to the projectile dimensions for this projectile to be effective, as shear strength is a volume effect. Large stress gradients exist between the area directly underneath the projectile core (compression) and the tension next to the contact area. Therefore, high yield stress aids in allowing the material to resist failure due to the large shear stresses generated near the impact site [13].

\section{Hugoniot elastic limit}

During the initial moments of an impact event, high transient pressures above the HEL are reached near the point of impact [14]. The Hugoniot Elastic Limit is defined as the yield stress of a material under uniaxial dynamic loading [15]. This is important since materials that are dynamically loaded above the HEL may exhibit a significant loss of yield strength compared to materials that are not as severely loaded. 


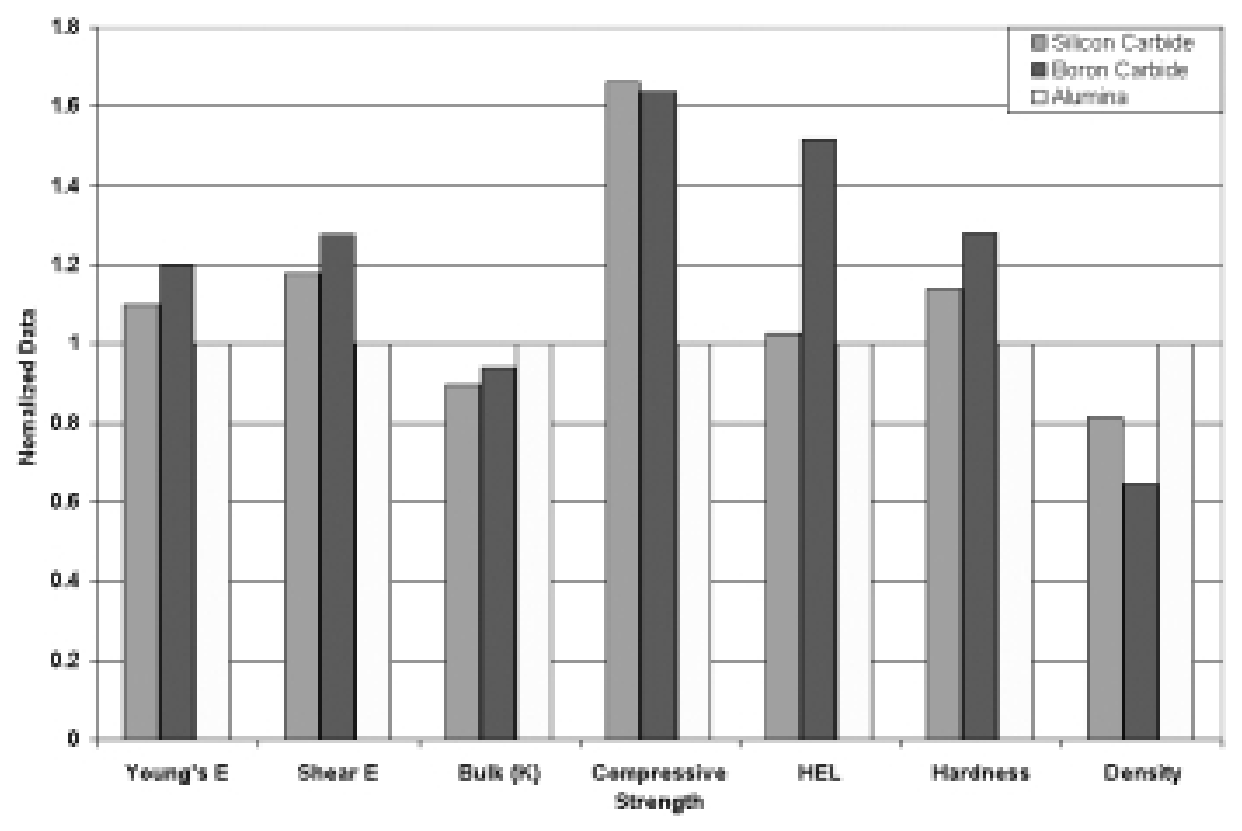

Fig. 3. Ceramic Properties Normalized by $99.9 \% \mathrm{Al}_{2} \mathrm{O}_{3}$.

\section{Ballistic efficiency}

The ballistic efficiency equation, as put forward by Rosenberg et al. [16], provides a means of evaluating ceramic performance based on ceramic areal density. This result is a performance measure used to evaluate the ceramic which is impact velocity and projectile dependent. Ballistic efficiency is calculated as:

$$
\eta=\frac{\rho_{\mathrm{AL} 6061}\left[P_{\mathrm{AL} 6061}\left(V_{s}\right)-P_{s}\right]}{\rho_{c} t_{c}}
$$

In this case, $\rho_{\mathrm{AL} 6061}$ is the density of the backing aluminum, $P_{\mathrm{AL} 6061}(\mathrm{VS})$ is the depth of penetration into unprotected monolithic aluminum as a function of the impact velocity of the projectile, $P_{s}$ is the residual depth of penetration into the backing aluminum, $\rho_{c}$ is the density of the ceramic and $t_{c}$ is the ceramic thickness. The numerator of the right side of the equation (less $\rho_{\mathrm{AL6061}}$ ), is a performance term while the denominator constitutes a weight term (areal density). By comparing the ballistic efficiencies, one may rank the ballistic performance of ceramics for a given projectile.

\section{Depth of penetration testing}

In this study, Depth of Penetration (DOP) testing was used to investigate the ballistic performance of four ceramics. A DOP value is obtained by measuring the depth of the impact crater in the backing material of protected and unprotected targets. By comparing the penetration of a projectile into a ceramic protected target and an unprotected target, a ceramic's ballistic performance may be determined. Figure 4 shows a schematic of a DOP test.

The backing used in these tests was 6061-T6 aluminum in the form of $\phi 152 \mathrm{~mm} \times 152 \mathrm{~mm}$ long cylinders. The DOP was measured from X-rays of the impacted cylinders.

The DOP experiments were conducted with projectile velocities of 750,850 and $910 \mathrm{~m} / \mathrm{s}$. The maximum variation in velocity was $+-14 \mathrm{~m} / \mathrm{s}$.

\section{Depth of penetration testing results experimental observations}

Observation of the $\mathrm{x}$-rays revealed that, in most cases, the core was severely fragmented. This is advantageous as one of the functions of the tile is to shatter or deform the projectile. However, in a few of the alumina and modified alumina test specimens, large pieces of the core survived the impact with the tile and penetrated the backing aluminum (see Fig. 5).

\section{Depth of penetration results}

At an impact velocity of $750 \mathrm{~m} / \mathrm{s}$, tiles protected by silicon carbide had the smallest depth of penetration. 

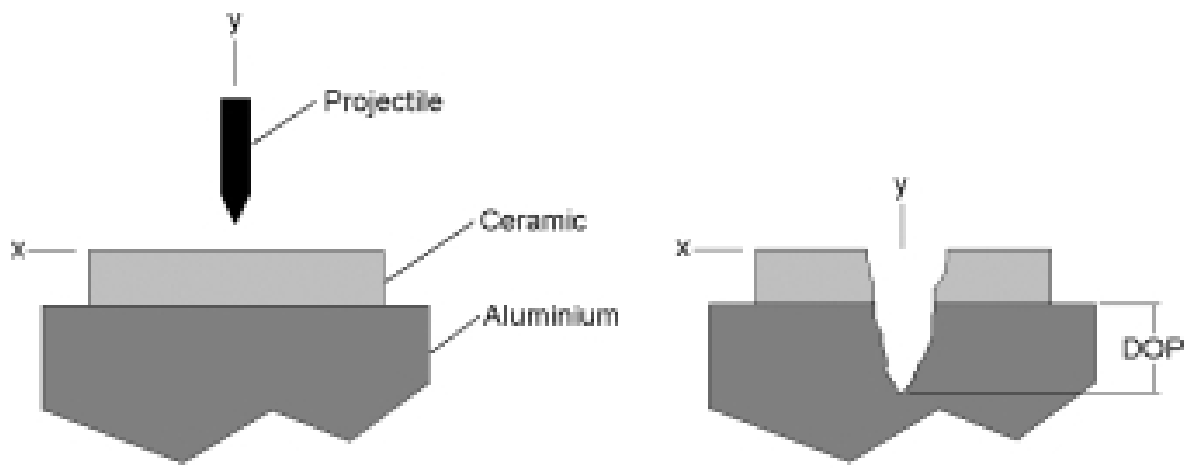

Fig. 4. Depth of penetration testing.

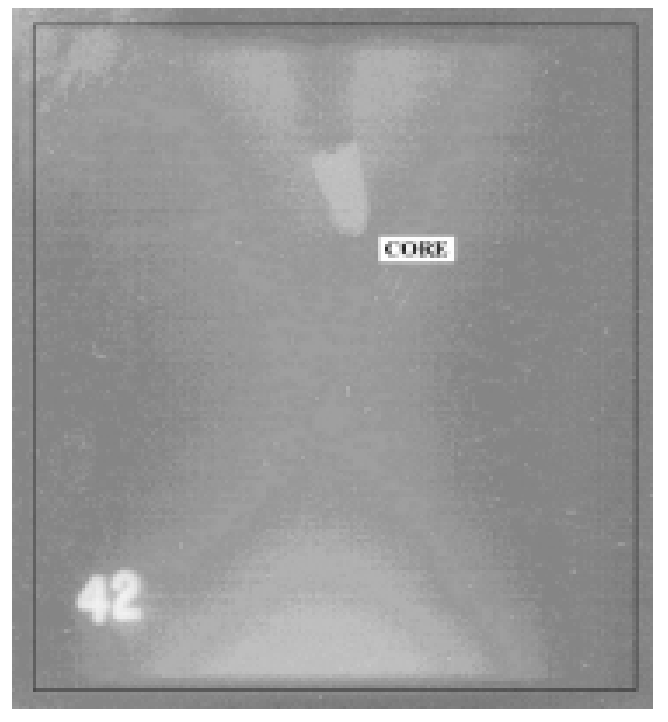

Fig. 5. X-Ray of Core Fragment ( $8.8 \mathrm{~mm}$ Alumina, $850 \mathrm{~m} / \mathrm{s}$ impact).

Alumina and modified alumina had much higher depths of penetration for the same impact velocity.

At an impact velocity of 850 and $910 \mathrm{~m} / \mathrm{s}$, the silicon carbide and boron carbide ceramics had similar DOPs, approximately five times less than the DOP for the alumina and modified alumina ceramic materials.

It was noticed that a significant amount of variation exists for the DOP measurements for identical impact conditions (i.e. same velocities, tile composition, tile thickness). Numerical studies regarding the distribution of flaws within a ceramic have determined that flaw distribution can alter the ballistic performance of a ceramic considerably [17]. As the cost in both material and time is large when conducting DOP tests, only a limited number of tests of the same impact condition were conducted. However, even with a significant amount of experimental scatter, the trends in the data were consistent at each impact velocity.

\section{Calculated ballistic efficiency}

Ballistic efficiency has been used in past studies to provide a means of ranking ceramic performance. The calculated ballistic efficiencies for the materials tested are shown in Figs 6 to 8.

Again the same trend is noted in the results. Silicon carbide and boron carbide show similar ballistic performance, with silicon carbide performing marginally better in this series of testing. This phenomenon is more pronounced in the results obtained from the $750 \mathrm{~m} / \mathrm{s}$ impact velocity as opposed to the two higher impact velocities. Alumina and modified alumina display lower ballistic efficiencies than silicon carbide and boron carbide. The ballistic efficiency of modified alumina is slightly better than standard alumina.

It is interesting to note that the efficiency of the silicon carbide and boron carbide increased as impact velocity increased. Since the penetration of the projectile into the aluminum was slight (except in the case of the $750 \mathrm{~m} / \mathrm{s} \mathrm{impact}$ ), this may be due to the defeat of the projectile within the ceramic. When the thickness of the ceramic is such that the projectile is defeated within the ceramic, the efficiency term is maximized. As a result, no increase in ballistic performance would be experienced, keeping all other parameters constant. As the ballistic efficiency is inversely proportional to tile thickness, this lowers the ballistic efficiency. This effect was identified by Woodward el al. [12], who noted that the construction of similar plots (i.e. (backing material density)X(DOP of ceramic protected backing material) vs. Areal Density) suggested a linear relationship between residual DOP and increasing ceramic thickness. However, it is also noted that when the ceramic becomes sufficiently thick to overmatch the projectile, the residual penetration into the backing material decreases [18]. 


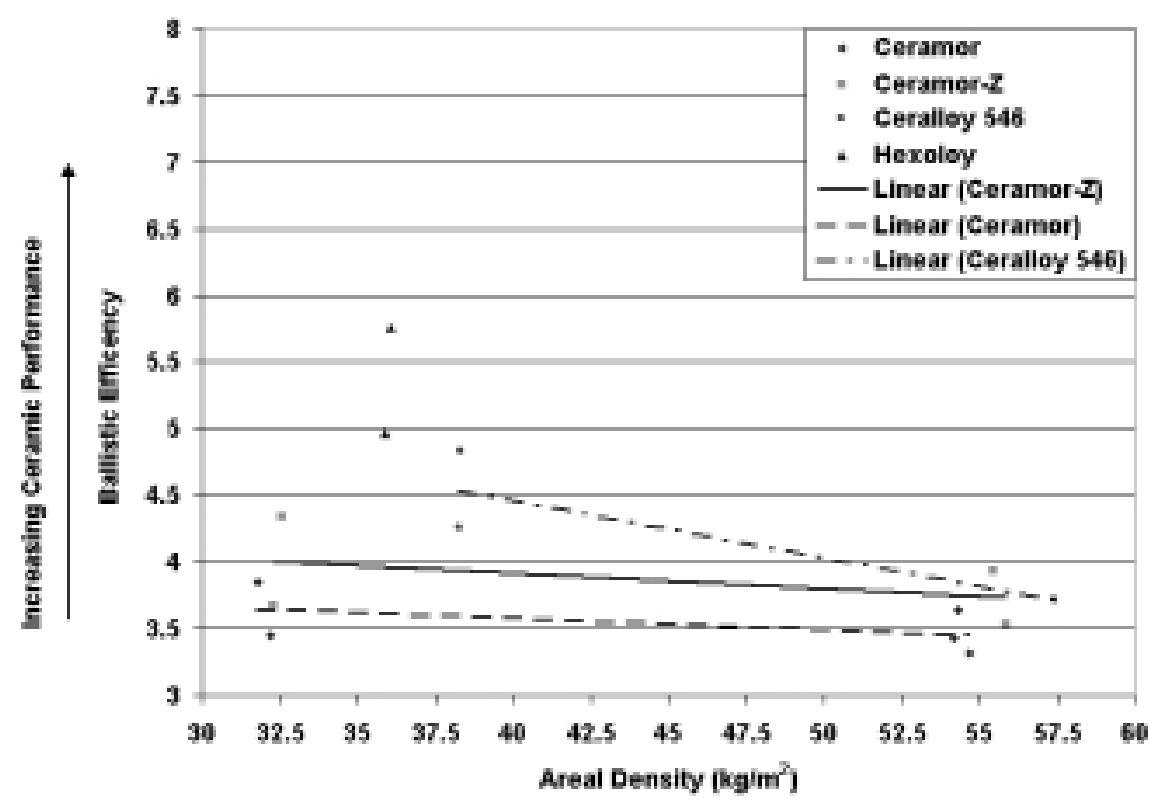

Fig. 6. Ballistic efficency vs. areal density for $750 \mathrm{~m} / \mathrm{s}$ impact.

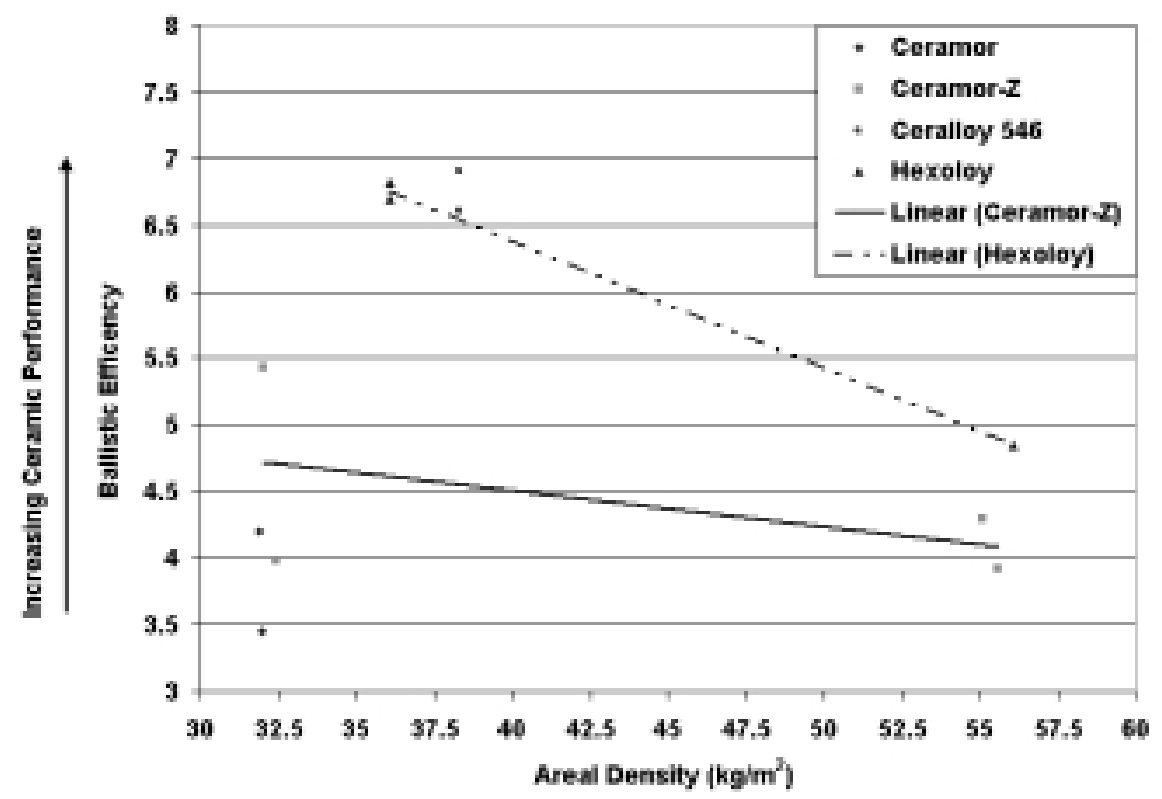

Fig. 7. Ballistic efficiency vs. areal density for $850 \mathrm{~m} / \mathrm{s}$ impact.

\section{Comments on the influence of material properties}

Silicon carbide and boron carbide have compressive strengths approximately 1.3 times greater than alumina. This would imply that silicon carbide and boron carbide should perform better in an impact event than alumina. The compressive strengths of silicon carbide and boron carbide are very similar, yet it is noted that silicon carbide outperforms both alumina and boron carbide at all of the impact velocities. As the areal densities of the tiles are similar (maximum difference of $2.3 \mathrm{~kg} / \mathrm{m}^{2}$ between thinner tiles tested), compressive strength (as determined in a quasi-static manner) must not play a dominant role in this particular impact event.

This may be due to traditional quasi-static compres- 


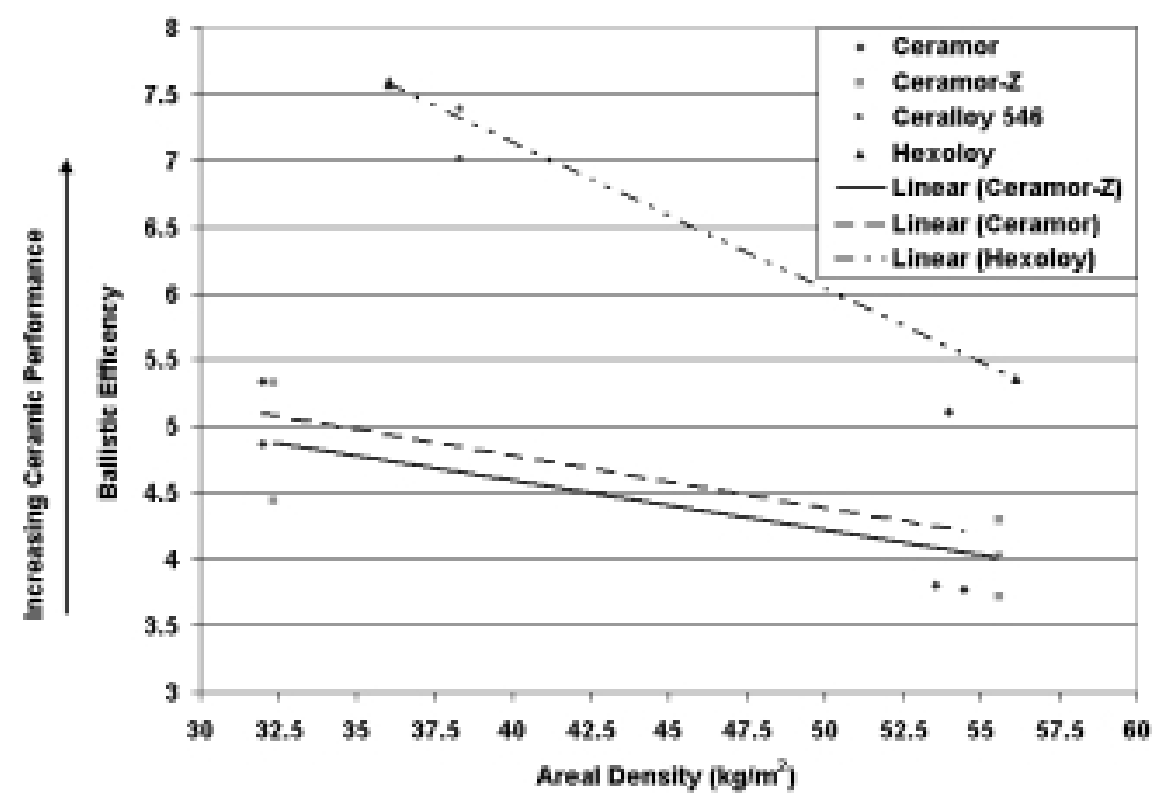

Fig. 8. Ballistic efficiency vs. areal density for $910 \mathrm{~m} / \mathrm{s}$ impact.

sive testing determining the strength of the weakest portion of the ceramic. At elevated strain rates, greater numbers of progressively smaller flaws are activated because the larger flaws do not relieve them. The measure of compressive strength is highly dependent upon the manufacture of the ceramic (i.e. amount of porosity, inclusions, and other flaws). Therefore, the compressive strength of ceramic determined in a quasi-static manner may not reflect the strength of ceramic in a high strain rate ballistic application.

All of the ceramics tested exhibited the ability to fracture the projectile core, provided that they were over a certain minimum thickness to completely fracture the core. It was noted in a previous section that large sections of intact core were able to survive the impact with the alumina tiles, whereas no appreciable sections of core survived the impact with a silicon carbide or boron carbide tile of a similar areal density. Although all ceramics tested had the necessary hardness to initiate fracture of the projectile, the tile thickness necessary to fracture the entire core was found to be more important.

Boron carbide has a higher Young's modulus than silicon carbide or alumina. Therefore, the impedance of boron carbide will be the highest and it should be the most advantageous ceramic in a ballistic impact. However, it was noted that the calculated ballistic efficiency of silicon carbide was greater than the ballistic efficiency of both boron carbide and alumina.

The properties of the ceramic that allow the tile to resist deformation do not correlate with the results.
Higher Young's and shear moduli are exhibited by boron carbide than the other ceramics tested. However, silicon carbide performs better. The bulk modulus of the materials was relatively similar, with all normalized values falling between 0.9 and 1 . As a result, the effect of modulus may not be apparent in these results.

The HEL of boron carbide was 1.5 times that of alumina. This would suggest, according to the works cited earlier, that a sample of boron carbide must be exposed to a shock greater than an equivalent sample of silicon carbide, which has an HEL similar to that of alumina, in order to suffer a loss of shear strength as mentioned in a previous section. The high HEL of boron carbide may not have been a major contributing property to these impact experiments as silicon carbide had a higher ballistic efficiency. Perhaps, the pressure in the ceramic beneath the impact zone that reaches the HEL is localized in the impact events that were studied. Therefore, the contribution of the HEL to the ballistic performance of the ceramic is limited.

\section{Limitations of ballistic efficiency for ceramic/composite armor}

Rosenberg et al. [16] developed the expression for ballistic efficiency based upon the use of a thick backing technique. Although this technique provides a means for ranking the performance of various ceramics mounted on thick backings, the result may vary for 
softer composite backing. Maffeo et al. [19] stated that there exists an ideal ratio of ceramic to composite thickness in hybrid armour. Too much ceramic increases the overall weight of the armor system while too little ceramic inhibits the armour's ability to fracture the core of the AP round. The means of propagating damage from a ceramic tile undergoing impact to the material which supports it is different between ceramic tiles supported in a semi-infinite (thick) backing configuration and a thin backing configuration. A ceramic tile bonded to a thin backing will not have as much support as a tile bonded to a thick backing. In this case, the backing material will experience loads that will cause it to deform or "dish" [20]. The backing is then susceptible to failure in bending or tension. In the thick backing configuration, the backing material fails through local deformation of the material. After eroding the ceramic, the remaining penetrator deforms the target material either by plugging for finite thickness armor or by cratering for a semi-infinite armor [20].

DOP testing and ballistic efficiency have provided a relative ranking of ceramics used in a thick backing configuration. Further testing will be done to investigate the effect of a soft backing on ceramic performance. Provided the relative rankings of the ceramics are identical, DOP testing will provide a simpler, less expensive means of evaluating the ballistic performance of a ceramic on a hard, semi-infinite backing and, at the same time, indicate the relative performance of the same ceramic compound on a softer composite backing.

\section{Conclusions ranking of various ceramics}

A depth of penetration study was conducted to evaluate the performance of alumina, modified alumina, silicon carbide and boron carbide when impacted by a $12.7 \mathrm{~mm}$ (0.50 Caliber) AP projectile. It was determined that silicon carbide has the best ballistic performance at the range of velocities tested. However, in many cases, the performance of boron carbide and silicon carbide were similar. The modified alumina did not appear to have increased ballistic properties relative to unmodified alumina. Both alumina compounds were outperformed by silicon carbide and boron carbide.

Future studies will utilize depth of penetration data in creating numerical simulations of ballistic impact involving the aforementioned projectile.

\section{References}

[1] E.C. Laible, ed., Ballistic Materials and Penetration Mechanics, Elsevier Scientific Publishing Company, New York, 1980.

[2] K.D. Rice et al., An Update on US National Institute of Justice Performance Standards for Personal Body Armour, Personal Armour Systems Symposium (2000), 235-244.

[3] J.-M. Salamé, Very Light Weight Inserts and Trauma Consequences, Personal Armour Systems Symposium (2000), 327336.

[4] T.A. Mirzeabasov et al., Further Investigation of Modeling System for Bullet-Proof Vests, Personal Armour Systems Symposium (2000), 211-234.

[5] D. Cronin et al., Numerical Modeling of Behind Armour Blunt Trauma, DREV CR 2000-146, Defence R\&D Canada, 2000.

[6] I.S. Chocron Benloulo et al., A New Analytical Model to Simulate Impact Onto Ceramic/Composite Armors, Int. J. Impact Engng 21(6) (1998), 461-471.

[7] D. Sherman et al., The Ballistic Failure Mechanisms and Sequence, J. Mater. Res. 12(5) (1997), 1335-1343.

[8] P.C. Den Reijer, Impact on Ceramic Faced Armor, Technische Univ. Delft (Netherlands), PhD Thesis, 1991.

[9] P. Riou et al., Visualization of the Damage Evolution in Impacted Silicon Carbide Ceramics, Int. J. Impact Engng 27(4) (1998), 225-235.

[10] R. Zaera et al., Modelling of the Adhesive Layer in Mixed Ceramic/Metal Armours Subjected to Impact, Composites 31(A) (2000), 823-833.

[11] D.A. Shockey et al., Failure Phenomenology of Confined Ceramic Targets and Impacting Rods, Int. J. Impact Engng 9(3) (1990), 263-275.

[12] R.L. Woodward et al., Ballistic Evaluation of Ceramics: Influence of Test Conditions, Int. J. Impact Engng 15(2) (1993), $119-124$.

[13] M.L. Wilkins, Mechanics of Penetration and Perforation, Int. J. Engng Sci 16 (1978), 793-807.

[14] J. Sternberg, Material Properties Determining the Resistance of Ceramics to High Velocity Penetration, J. Appl. Phys 65(9) (1989), 3417-3424.

[15] Z. Rosenberg et al., On the Influence of the Loss of Shear Strength on the Ballistic Performance of Brittle Solids, Int. J. Impact Engng 9(1) (1990), 45-49.

[16] Z. Rosenberg et al., The Relation Between Ballistic Efficiency and Compressive Strength of Ceramic Tiles, Impact 87 conference proceedings, 1987, pp. 491-498.

[17] R. Delagrave, A Numerical Investigation of the Results Scatter Obtained with the Depth of Penetration Technique, DREV TM - 9612, Defence R\&D Canada, 1997.

[18] T.J. Moynihan, Application of the Depth-of-Penetration Test Methodology to Characterize Ceramics for Personal Protection, ARL - TR - 2219, 2000.

[19] M. Maffeo, Composite Materials for Small Arms (Ball Round) Protective Armor, 32nd International SAMPE Technical Conference, 2000, pp. 768-777.

[20] R.L. Woodward, A Simple One-Dimensional Approach to Modeling Ceramic Composite Armour Defeat, Int. J. Impact Engng 9(4) (1990), 455-474. 

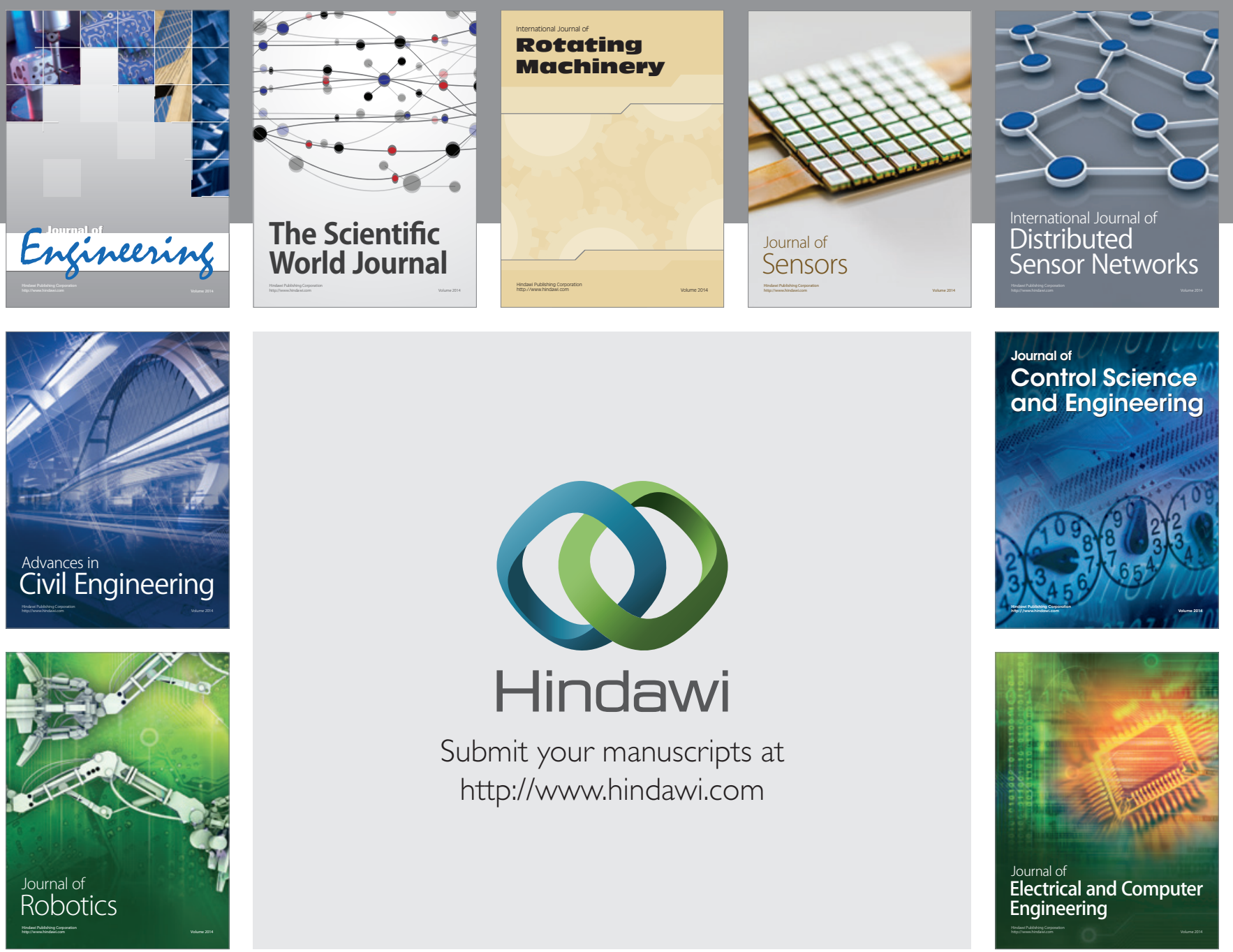

Submit your manuscripts at

http://www.hindawi.com
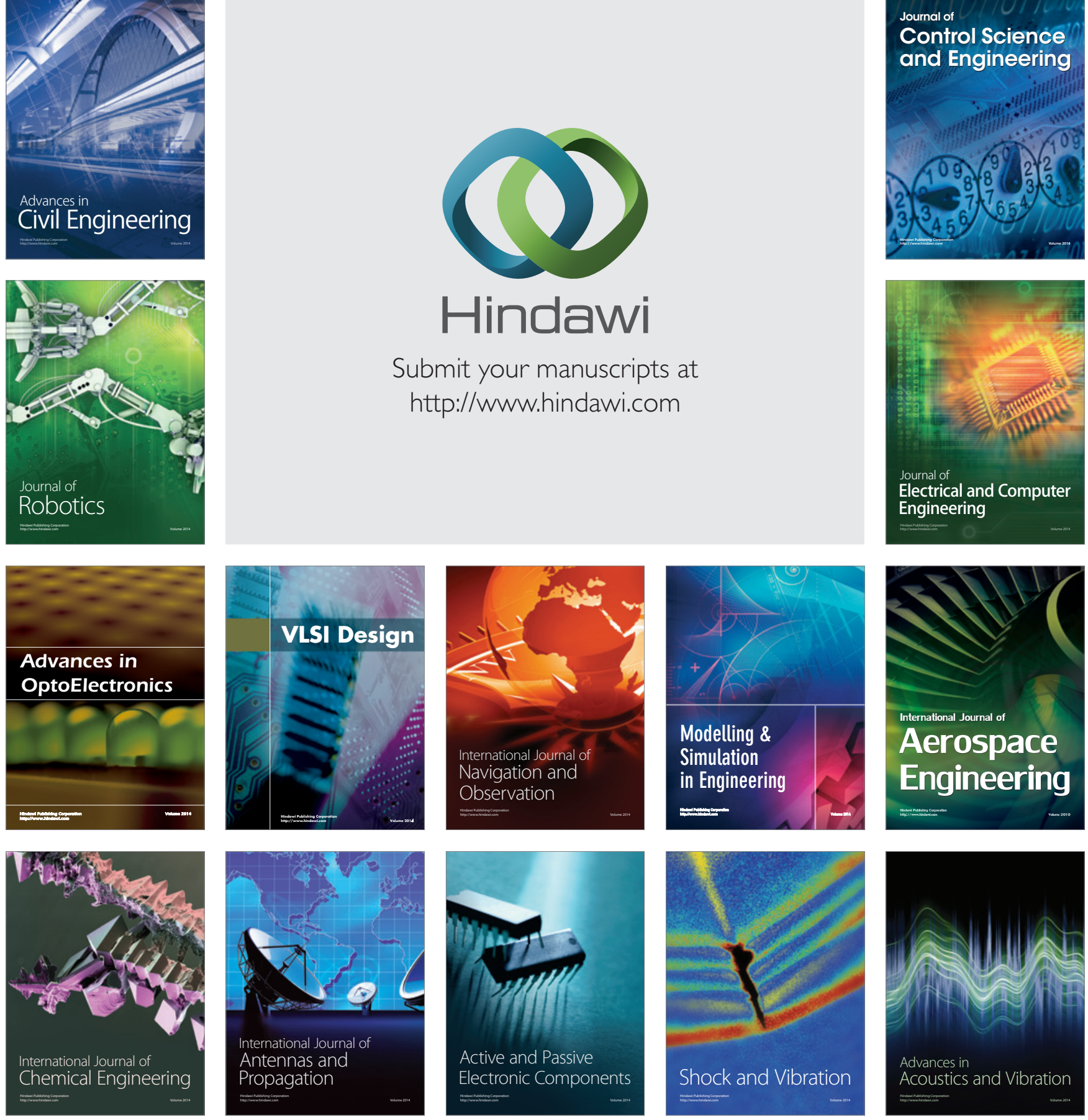